\title{
Pembuatan Media Majalah Pada PT. Serpong Tatanan Kota
}

\author{
Wahyu Hidayat*1 $^{*}$, Mintauli Debataraja ${ }^{2}$, Syifa Kamila Achmad ${ }^{3}$ \\ ${ }^{1,3}$ Program Studi Teknik Informatika, Fakultas Sains and Teknologi, Universitas Raharja \\ ${ }^{2}$ Dosen Program Studi Akuntansi, Fakultas Ekonomi dan Bisnis, Universitas Raharja \\ E-mail: * ${ }^{1}$ wahyu.hidayat@ raharja.info, ${ }^{2}$ mintauli@ raharja.info, ${ }^{3}$ syifa.kamila@ raharja.info
}

\begin{abstract}
Abstrak
Dalam desain komunikasi visual, memiliki banyak manfaat. Salah satunya di bidang bisnis, desain komunikasi visual merupakan bagian penting dari bidang usaha.Penelitian bertujuan tentang Media informasi yang ada sebelumnya dinilai kurang dalam penyampaiannya, karena masih berbentuk banner dan foto belum adanya penjelasan tentang PT. Serpong Tatanan Kota, sehingga kurang menarik masyarakat.Tujuan penelitian membuatkan desain majalah yang akan dibuat dengan desain yang minimalis dan elegan, untuk meningkatkan daya tarik pelanggan untuk PT. Serpong Tatanan Kota Adapun manfaat dari penelitian ini adalah masyarakat dapat mengetahui informasi yang ada di PT. Serpong Tatanan Kota. Metode penelitian yang di gunakan untuk majalah yaitu Metode pengumpulan data dengan Observasi ketempat yang di tuju secara langsung, wawancara atau dari kajian pustaka, Analisa Perancangan Media dengan pengumpulan data informasi yang didapatkan akan diproduksi menggunakan software grafis seperti adobe photoshop cs6,Konsep Desain Perancangan media desain ini melalui beberapa proses pembuatan agar mendapat gambaran tentang projek yang di buat., Layout Konferenshif dan Final Artwork. hasil penelitian ini media dapat meningkatkan pencitraan PT. Serpong Tatanan Kota, Dalam merancang media majalah menampilkan secara jelas identitas PT. Serpong Tatanan Kota, Visi misi, keunggulan, dengan di dukung informasi yang detail, jelas dan up to date, Alat penunjang perancangan media menggunakan aplikasi Adobe Photoshop CS6.
\end{abstract}

Kata kunci : informasi, promosi majalah.

\begin{abstract}
In visual communication design, it has many benefits. One of them is in the field of business, visual communication design is an important part of the business field. Research aimed at existing information media is considered less in its delivery, because it is still in the form of banners and photos there is no explanation about PT. Serpong City Order, so it is less attractive to the community. The purpose of the research is to create a magazine design that will be made with a minimalist and elegant design, to increase customer attractiveness for PT. Serpong City Order As for the benefit of this research is that the public can know the information in PT. Serpong City Order. Research method used for magazines is data collection method with observation to the place intended directly, interview or from the study of the library, Analysis of Media Design with data collection of information obtained will be produced using graphic software such as adobe photoshop cs6, Design Concept Design media design through several processes of making in order to get an overview of the project created., Layout Konferenshif and Final Artwork. the results of this research media can improve imaging PT. Serpong City Order, In designing the magazine media clearly displays the identity of PT. Serpong City Order, Vision mission, excellence, with the support of detailed information, clear and up to date, media design support tools using Adobe Photoshop CS6 application.
\end{abstract}

Keywords : information, promotion of magazines. 


\section{PENDAHULUAN}

Dalam desain komunikasi visual, memiliki banyak manfaat. Salah satunya di bidang bisnis, desain komunikasi visual merupakan bagian penting dari bidang usaha. Desain komunikasi visual dapat digunakan sebagai media promosi seperti iklan yang dapat menarik perhatian konsumen. Dengan menggunakan media cetak yang akan disampaikan kepada konsumen disampaikan secara penuh sehingga mudah dipahami ${ }^{[1]}$.

Penggunaan desain komunikasi visual sebagai alat promosi akan membuat produk memiliki nilai jual yang tinggi, tentunya dengan media promosi yang inovatif, kreatif dan interaktif. Desain komunikasi visual adalah pilihan yang tepat untuk promosi, karena mampu menggabungkan gambar, suara, dan gerakan untuk membuat produk yang ditawarkan lebih menarik $^{[2] .}$

Desain modern merupakan keseluruhan proses pemikiran yang akan membentuk sesuatu, dengan menggabungkan fakta, konstruksi, fungsi dan estetika. Sebagai suatu kagiatan yang menyangkut alam pikiran dan perbuatan manusia untuk menjawab kebutuhan-kebutuhan ketika berhadapan dengan lingkungannya, menjadikannya sangat erat dengan kebudayaan. Yakni kebudayaan yang benar-benar dihayati, bukan kebudayaan dalam arti sekumpulan sistem bentuk, warna dan gerak dari masa lampau. Pada hakikatnya desain grafis merupakan sebuah rancangan maupun karya desain yang menggunakan desain grafis atau tulisan. Untuk kepentingan mengkomunikasikan informasi dalam bentuk visual. Hal ini berguna untuk kepentingan promosi, iklan, publikasi maupun layanan lainnya ${ }^{[3] .}$

Dengan desain komunikasi visual berbentuk majalah yang akan penulis buat untuk PT. Serpong Tatanan Kota akan membuat membuat majalah sedetail dan menarik seperti, profil perusahaan, visi \& misi, jenis perumahan, keuntungan, fasilitas dan kegiatan, dengan beberapa hal ini akan sarat dengan desain yang menarik mungkin. Dalam rangka meningkatkan pemahaman bagi calon nasabah baru tentang informasi PT. Serpong Tatanan Kota.

Sedangkan PT. Serpong Tatanan Kota juga tidak memiliki media informasi dan promosi seperti majalah. Majalah merupakan salah satu bentuk media informasi dalam dalam memberikan informasi, dan berfungsi sebagai image yang menjadi daya tarik dalam penyampaian informasi dan promosi secara lebih lengkap dan jelas. Oleh karena itu dengan terciptanya media desain majalah, informasi dan promosi yang biasanya hanya berbentuk visual maka penulis akan membuat desain yang menarik dan jelas dalam desain majalah. Yang akan dibuat dengan desain yang minimalis dan elegan, untuk meningkatkan daya tarik pelanggan untuk PT. Serpong Tatanan Kota.

\section{METODE PENELITIAN}

Beberapa metode penelitian yang di gunakan untuk majalah yaitu : (1) Metode pengumpulan data, yaitu metode yang digunakan untuk mendapatkan data dengan pengamatan langsung (Observasi) ketempat yang di tuju secara langsung, interview atau dari kajian pustaka (2) Analisa Perancangan Media dengan pengumpulan data informasi yang didapatkan akan diproduksi menggunakan software grafis seperti adobe photoshop cs6, (3) Konsep Desain. Perancangan media desain ini melalui beberapa proses pembuatan agar mendapat gambaran tentang projek yang di buat.

Penelitian yang dilakukan oleh Yuliati dkk, (2014) $)^{[4]}$ "Mobile Augmented Design Menggunakan Metode Pengembangan Perancangan Sistem Multimedia Interaktif (Studi Kasus: Brosur di Sekolah Tinggi Teknologi Dumai "menjelaskan tentang peningkatan brosur media promosi yang selama ini digunakan untuk menarik calon mahasiswa dan memberikan informasi terkait promosi yang ditawarkan oleh Sekolah Tinggi Teknologi Dumai yang mengembangkan media brosur Mobile Augmented Reality secara real time menggunakan Metode interaktif Pengembangan Perancangan Sistem Multimedia Menggunakan Andoid offline. Selanjutnya. Ivoni Putri Damayanti dan Bijaksana Prabawa (2017) "Perancangan Media Promosi untuk 
Objek Wisata Taman Air Gua Sunyaragi Di Cirebon"Cirebon memiliki kekayaan peninggalan sejarah dan budaya yang begitu tinggi, akan tetapi kekuatan tersebut belum maksimal untuk meningkatkan wisatawan ke kota Cirebon dikarenakan promosi yang kurang optimal yang menyebabkan turun minat masyarakat untuk berkunjung.

Lalu, Penelitian yang dilakukan oleh Giandari Maulani, dkk (2017) "Desain Media Komunikasi Visual Berbentuk Tabloid Sebagai Sarana Promosi SMK Mandiri 2 "Dalam penelitian ini dijelaskan tentang promosi sekolah beserta informasi lainnya yang bertujuan untuk menginformasikan sekolah kepada masyarakat. Untuk menyampaikan suatu pesan melaui tabloid dinilai efektif karena memberikan berbagai informasi di sekolah SMK Mandiri 2. Selanjutnya

Penelitian yang dilakukan oleh Dewi Immaniar, dkk (2014) $)^{[7]}$, yang berjudul "Enriching Media Merchandise penunjang sarana Promosi Studi Kasus Pada Book-Store". Penelitian ini membahas media promosi kreatif dan beragam yang dibutuhkan perusahaan.

Dan yang terakhir Research done Yan Jiang and Wenlong Liu (2015:49) ${ }^{[8]}$ " Mind Mapping Application in Teaching Poster Design and Classroom Practice Guide. Based on the characteristics of radioactive brain thinking, British educator Tony Buzan first proposed the two concepts of "Luminous Thinking" and "Mind Mapping." And Mind Maps are external manifestations of the brain's radioactive thinking. With the mastery of mind maps, this way of thinking has been widely used in various aspects. life and work, including learning, communication, management, etc.Because it can effectively stimulate human creativity, in recent years this way of thinking has also been widely used. increasingly recognized and adopted in the field of art and design. For design students, mind maps can help the active thinking brain to think actively and break conventional thinking. Within the scope of the concept that has been confirmed, Mind Maps provide guidance on the direction of thinking. And, a lot of inspiration then comes to mind. This process is very interesting and effective; For instructors, good use of mind maps to guide students keeps the class active and significantly improves the quality and quantity of designs. Hence, proper use of mind maps increases the efficiency and quality of teaching

(Berdasarkan karakteristik pemikiran otak radioaktif, pendidik Inggris Tony Buzan pertama kali mengusulkaa dua konsep - "Radiant Thinking" dan "Mind Mapping "'". Peta pikiran adalah manifestasi eksternal dari pemikiran otak radioaktif. Dengan penguasaan peta, cara berpikir ini telah banyak digunakan dalam berbagai aspek kehidupan dan pekerjaan, termasuk dalam pembelajaran, komunikasi, manajemen, dll. Karena dapat secara efektif menggugah kreativitas manusia, dalam beberapa tahun terakhir cara berpikir ini juga telah dikenal. dan diadopsi di bidang seni dan desain. Bagi pembelajar desain, peta pikiran dapat membantu otak berpikir aktif, berpikir aktif, dan memecahkan pikiran berpikir konvensional. Dalam ruang lingkup konsep yang dikonfirmasi, peta pikiran memberikan panduan untuk berpikir. Dan, banyak inspirasi kemudian muncul di benak. Proses ini sangat menarik dan efektif; Bagi instruktur, penggunaan peta pikiran yang baik untuk membimbing siswa membuat kelas tetap aktif dan secara signifikan meningkatkan kualitas dan kuantitas desain. Karenanya, penggunaan peta pikiran yang tepat meningkatkan efisiensi dan kualitas.

\section{HASIL DAN PEMBAHASAN}

\subsection{Perancangan Media}

Perancangan desain majalah yang memuat sampul depan dan belakang, visi misi perusahaan, profile lengkap perusahaan, keunggulan perusahaan, kegiatan usaha dan property investasi, pusat perbelanjaan, perkantoran dan property serta kontak dan alamat perusahaan. Perancangan akan di buat berbentuk buku yang dirancang melalui desain komunikasi visual yang kreatif dan menarik. 


\section{Tujuan Media}

Untuk penunjang promosi dan informasi perusahaan dan menjadikan sistem promosi yang lebih efektif dan jelas diharapkan dapat meningkatkan daya tarik dari masyarakat khusunya calon customer yang ingin melakukan pembelian rumah ke PT. Serpong Tatanan Kota.

\section{Program Media}

Media desain majalah yang telah disepakati oleh stakeholders dan Direktur Operasional, Penulis mengusulkan design magazine sebagai media program pendukung informasi dan promosi yang digunakan pada tahun 2020 dan informasi terbaru setiap tahun sehingga lebih banyak orang tahu tentang PT. Serpong Tatanan Kota.

\subsection{Perancangan Pesan (Konsep Kreatif)}

Media design magazine dibuat oleh penulis berisi informasi berupa data, layout yang tertata rapi dan gambar yang menarik sehingga informasi mudah diaplikasikan, desain dibuat agar terlihat sederhana dan rapi.

\section{Tujuan Kreatif}

Dari tampilan bentuk pesan tersebut peneliti bertujuan untuk memberikan gambaran tentang tampilan dan isi majalah sebagai tambahan daya tarik dan wawasan tentang media majalah yang akan digunakan sebagai media informasi dan promosi.

\section{Strategi Kreatif}

PT. Serpong Tatanan Kota, Koperasi pinjaman yang diberikan, keuntungan, fasilitas, kegiatan, kontak dan alamat tempel dibuat dengan menggunakan pesan visual dari elemen grafis yang tersusun rapi, sehingga desain terlihat menarik yang mempunyai kesan minimalis dan elegan namun tetap mengandung kesan yang baik dan jelas. pesan agar mudah dipahami oleh pembaca.

3. Jadwal Penelitian

Tabel 3.1 Jadwal Penelitian

\begin{tabular}{|c|c|c|c|c|c|c|c|c|c|c|c|c|c|c|c|c|}
\hline \multirow{2}{*}{ Media Majalah } & \multicolumn{4}{|c|}{$\begin{array}{l}\text { APRIL } \\
2020\end{array}$} & \multicolumn{4}{|c|}{$\begin{array}{l}\text { MEI } \\
2020\end{array}$} & \multicolumn{4}{|c|}{$\begin{array}{l}\text { JUNI } \\
2020\end{array}$} & \multicolumn{4}{|c|}{$\begin{array}{l}\text { JULI } \\
2020\end{array}$} \\
\hline & 1 & 2 & 3 & 4 & 1 & 2 & 3 & 4 & 1 & 2 & 3 & 4 & 1 & 2 & 3 & 4 \\
\hline Cover Majalah & & & & & & & & & & & & & & & & \\
\hline Gedung Sekolah & & & & & & & & & & & & & & & & \\
\hline Sejarah Sekolah & & & & & & & & & & & & & & & & \\
\hline $\begin{array}{l}\text { Visi, Misi dan } \\
\text { Tujuan Sekolah }\end{array}$ & & & & & & & & & & & & & & & & \\
\hline Keunggulan & & & & & & & & & & & & & & & & \\
\hline Program Studi & & & & & & & & & & & & & & & & \\
\hline $\begin{array}{l}\text { Akreditasi dan } \\
\text { Penghargaan }\end{array}$ & & & & & & & & & & & & & & & & \\
\hline $\begin{array}{l}\text { Kegiatan } \\
\text { Pelatihan Bisnis }\end{array}$ & & & & & & & & & & & & & & & & \\
\hline Fasilitas Sekolah & & & & & & & & & & & & & & & & \\
\hline $\begin{array}{l}\text { Kegiatan Belajar } \\
\text { Mengajar }\end{array}$ & & & & & & & & & & & & & & & & \\
\hline $\begin{array}{l}\text { Kegiatan } \\
\text { Praktikum di Lab } \\
\text { Komputer }\end{array}$ & & & & & & & & & & & & & & & & \\
\hline Kegiatan LDK & & & & & & & & & & & & & & & & \\
\hline
\end{tabular}




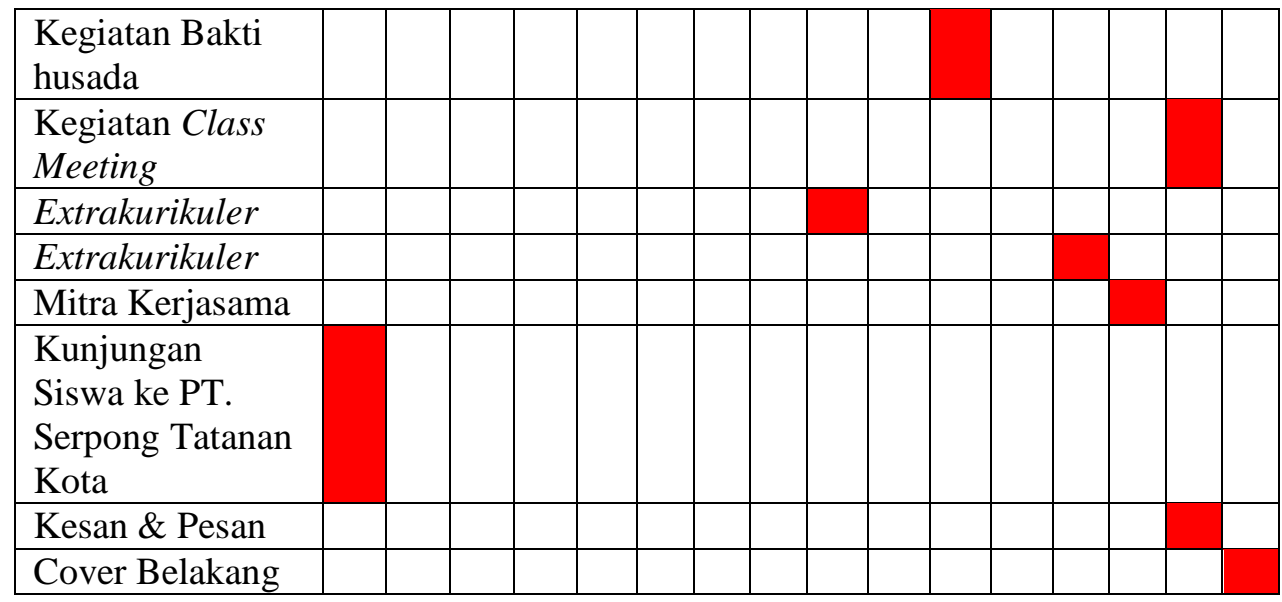

\subsection{Perancangan Visual (Konsep Visual)}

Dengan menampilkan buku majalah dengan kesan sederhana, meliputi tata letak, warna, dan gambar. Presentasi desain majalah dengan tetap mempertahankan warna asli.

1. Tujuan Visual

Penampilan visual setiap desain bertujuan untuk menyampaikan pesan majalah kepada publik. Nuansa yang ingin peneliti sampaikan pada masing-masing desain ini adalah menyampaikan pesan yang menarik.

\section{Strategi Visual}

Visualisasi Gaya Presentasi menggunakan gaya minimalis tetapi masih tampak modern. Desain media majalah dibuat dengan menyusun objek gambar dan mengedit orientasi setiap aktivitas, tata letak gambar dan teks sebagai dukungan untuk kegiatan manajemen editorial menggunakan adobe photoshop CS6.

\section{Penulisan Naskah}

Desain majalah sebagai penunjang promosi dan informasi PT. Serpong Tatanan Kota, penulis membuat desain berisikan gambar yang disertakan teks (tulisan), teks yang dibuat melalui pemiihan font teks (jenis tulisan).

\section{Pengarah Visualisasi (Art Directing)}

Desain majalah semakin menarik dan untuk meningkatkan citra perusahaan diperlukan arahan dalam mendesain tampilan desain majalah mulai dari arah layout, jenis huruf, gaya tampilan visual dan warna yang serasi 
5. Proses Desain (Designing)

a. Layout Kasar

\section{Layout kasar cover depan}

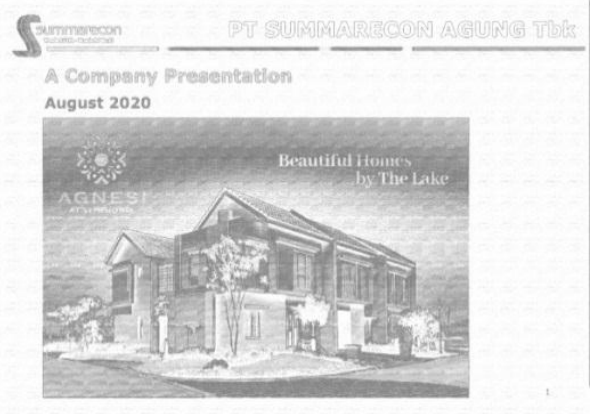

Gambar 4.1. Layout kasar Cover Depan

3. Layout kasar Menampilkan Plant For 2020

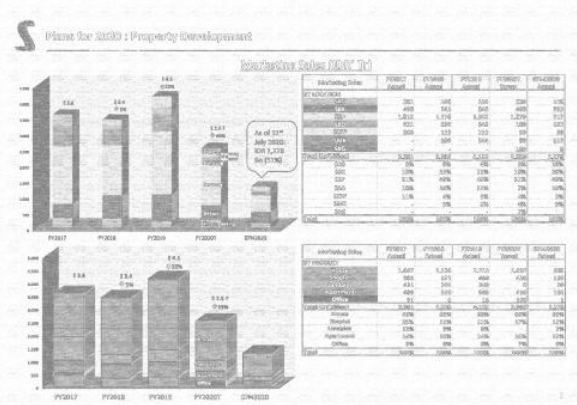

Gambar 4.3. Layout kasar

Menampilkan Plant For 2020

5. Layout kasar Corporate Information

$\checkmark$

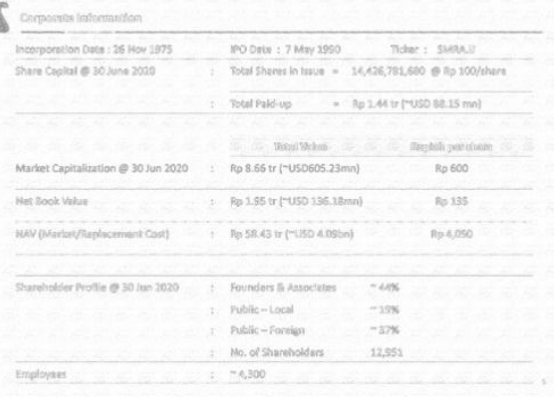

Gambar 4.5. Layout kasar Corporate Information
2. Layout Kasar Daftar Isi

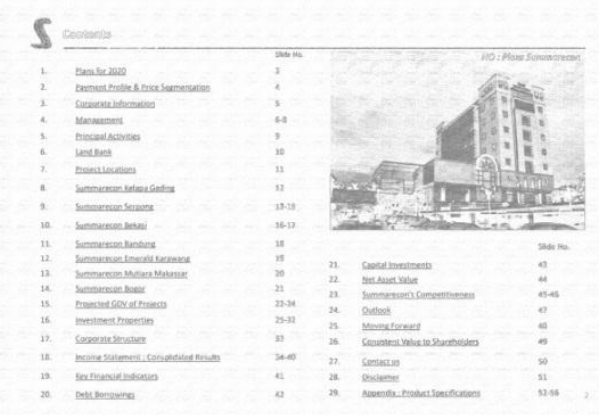

Gambar 4.2. Layout Kasar Daftar Isi

\section{Layout kasar Price Segmentation \&} Payment Profile

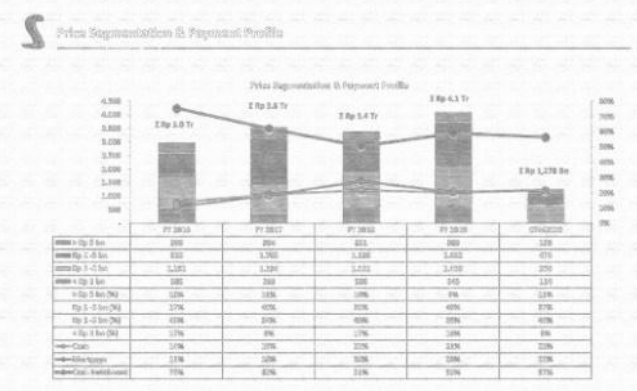

Gambar 4.4. Layout kasar Price Segmentation \& Payment Profile

6. Layout kasar Board of Commissioners (5 Member)

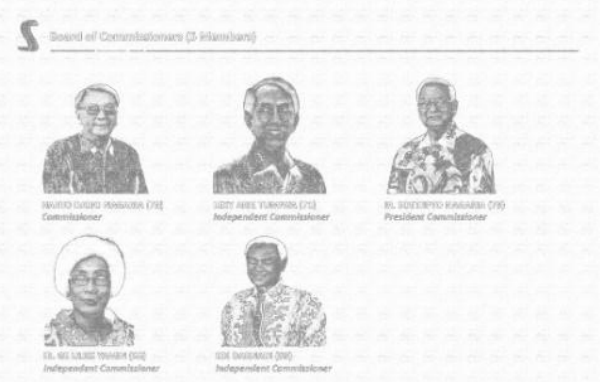

Gambar 4.6. Layout kasar Board of Commissioners (5 Member) 
7. Layout kasar Board of Director (8 Member)

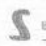

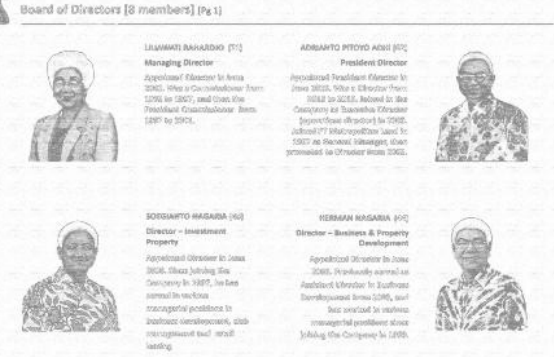

Gambar 4.7. Layout kasar Board of Director (8 Member)

9. Layout kasar Principal Activities.

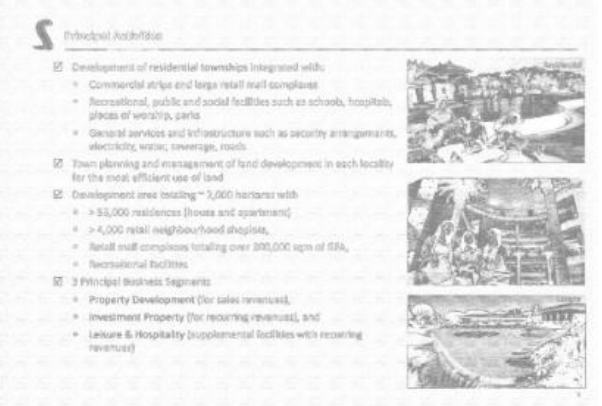

Gambar 4.9. Layout Kasar Principal Activities

\section{Layout kasar Cover Belakang}

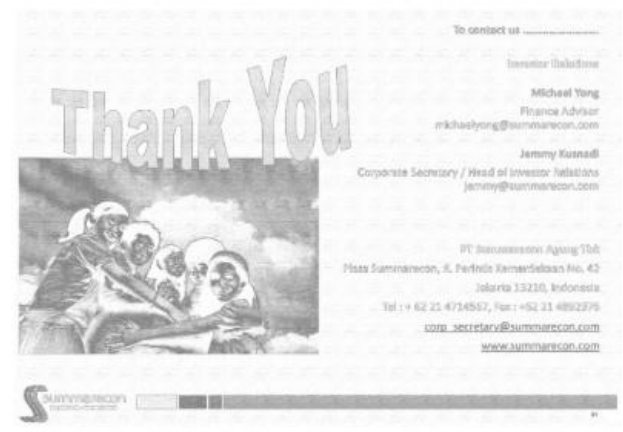

8.Layout kasar Board of Director (8 Member)

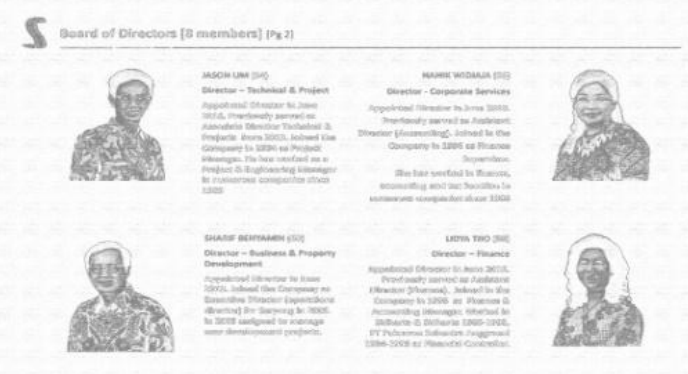

Gambar 4.8. Layout kasar Board of Director (8 Member)

\section{Layout kasar Landbank, Planned Acquistions}

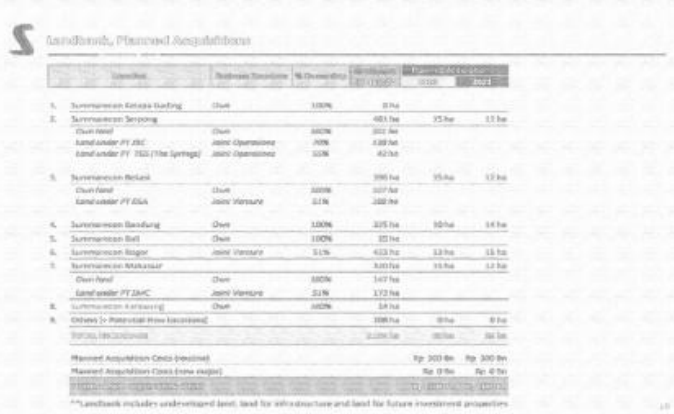

Gambar 4.10. Layout Kasar Landbank, Planned Acquistions

Gambar 4.1.1 Layout kasar Cover Belakang

b. Layout Komprehensif

Layout Komprehensif adalah suatu gambar yang sudah mendekati komposisi final, dalam hal ini komposisi gambar yang pada umumnya disajikan dalam bentuk warna. Font yang digunakan adalah Garde, Magneto, Calibri, Ceria Lebaran. Ukuran Media berukuran A4 Landscape, Warna yang digunakan warna yaitu: Putih dan Orange serta Bahan cetak yang digunakan adalah bahan Art Carton. 
Print ISSN: 2723-1992

Online ISSN: 2723-200X

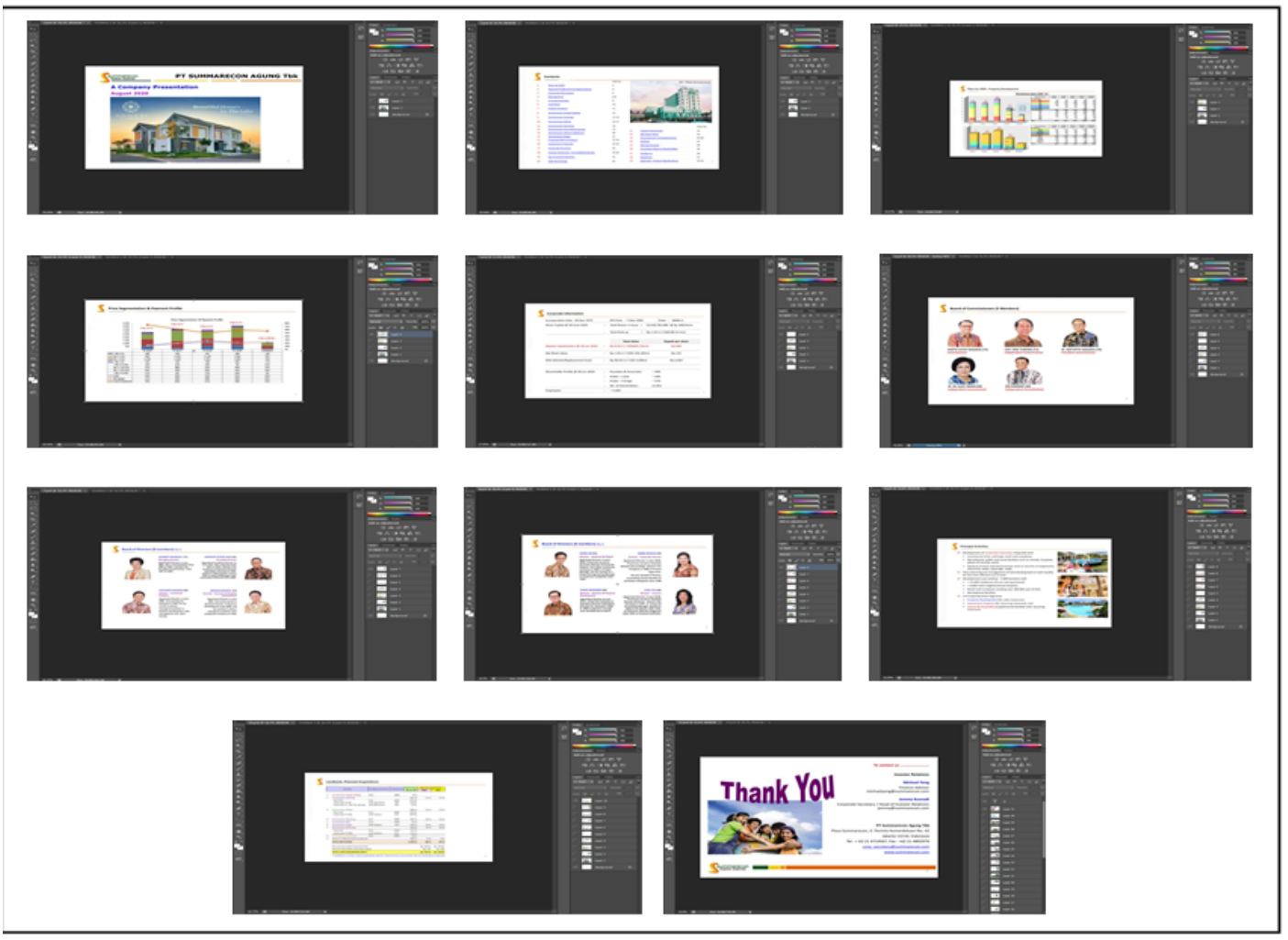

Gambar 12. Layout Komprehensif

c. Final Artwork

Berikut ini adalah Final Artwork yang merupakan tahap final dari pembuatan majalah PT. Serpong Tatanan Kota :

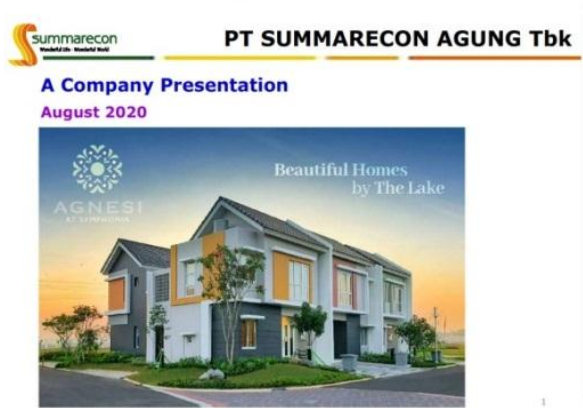

Gambar 4.13. Final Artwork Cover Depan

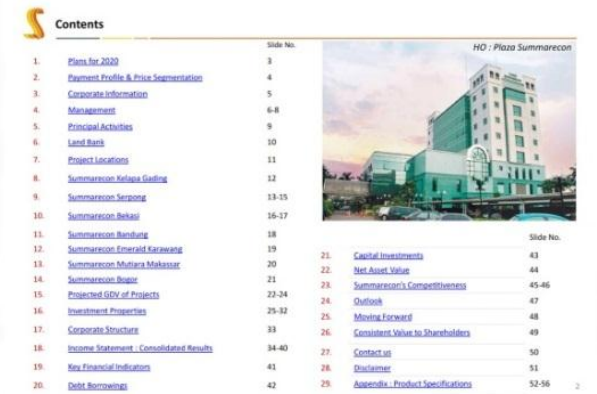

Gambar 4.14. Final Artwork Daftar Isi 
Print ISSN: 2723-1992

Online ISSN: 2723-200X

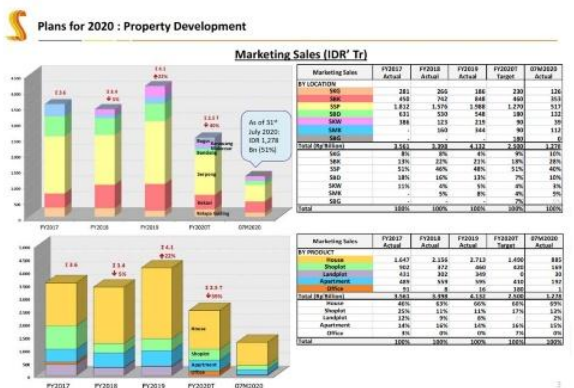

Gambar 4.15. Final Artwork Plant For 2020

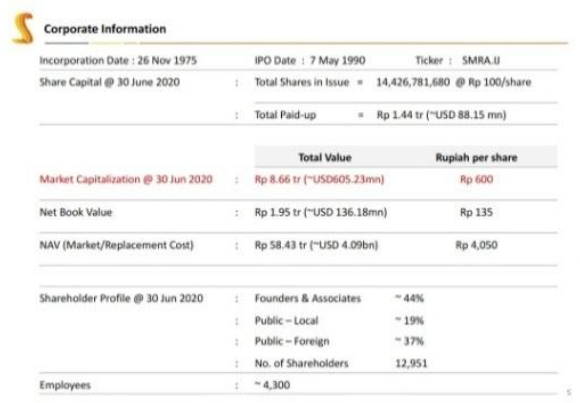

Gambar 4.17. Final Artwork Corporate Information

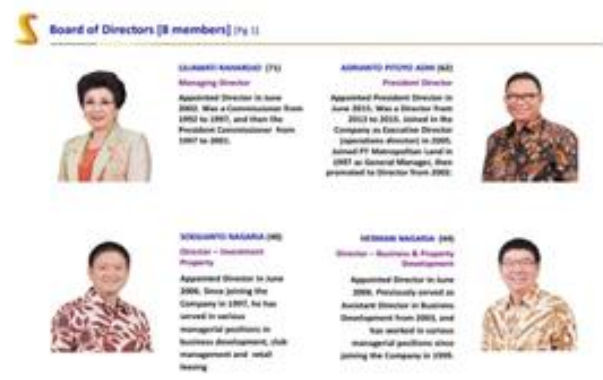

Gambar 4.19. Final Artwork Board of Commissioners (5 Member)

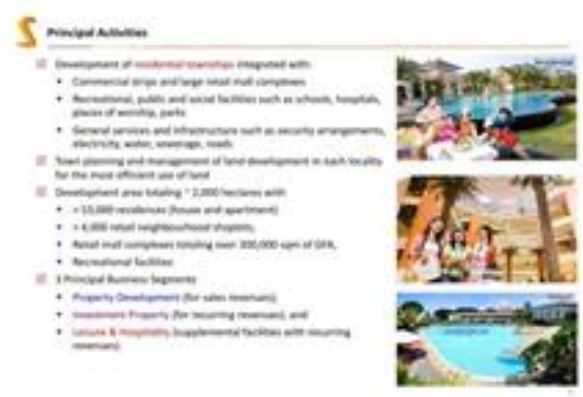

Gambar 4.21. Final Artwork Principal Activities

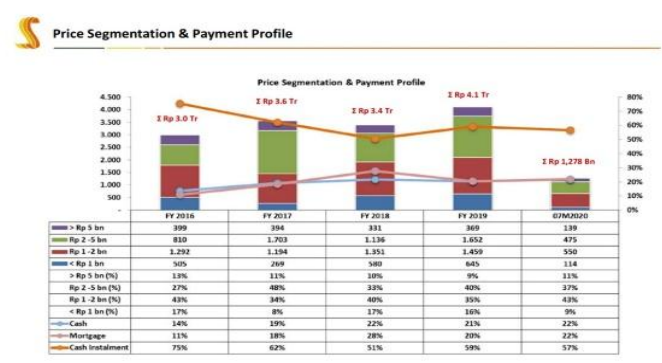

Gambar 4.16. Final Artwork Price Segmentation \& Payment Profile

$\int$ Boardo of commisisoners (s smemeres)
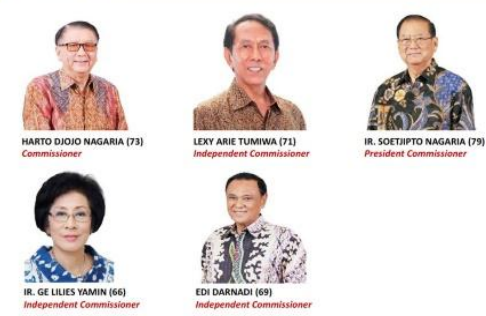

Gambar 4.18. Final Artwork Board of $(5$ Member) Commissioners

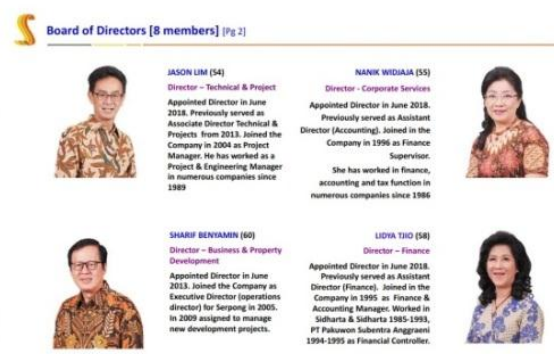

Gambar 4.20. Final Artwork Board of Director (8 Member)

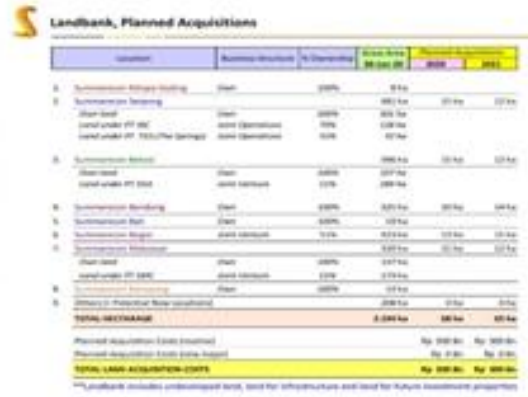

Gambar 4.22. Final Artwork Landbank, Planned Acquistions 


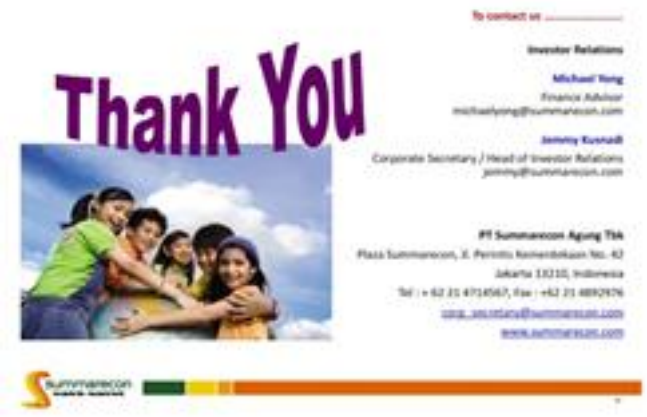

Gambar 4.23. Final Artwork Cover

Belakang

\section{KESIMPULAN}

Dalam pembuatan media profile majalah yang baik, harus memperhatikan faktor faktor yang berhubungan dengan PT. Serpong Tatanan Kota yang bersangkutan. Dalam hal ini penulis menyesuaikan dengan keinginan stakeholder, mulai dari pembuatan tampilan, isi majalah dan penutup. Hal ini bertujuan untuk memperkuat media desain berbentuk majalah dalam hal mempromosikan.

\section{SARAN}

Dari hasil rancangan media agar dapat meningkatkan pencitraan PT. Serpong Tatanan Kota, Dalam merancang media majalah menampilkan secara jelas identitas PT. Serpong Tatanan Kota, Visi misi, keunggulan, dengan di dukung informasi yang detail, jelas dan up to date, Seperti rancangan media majalah berisikan kegiatan, daftar pinjaman, dengan tampilan yang menarik, sehingga dapat meningkatkan image PT. Serpong Tatanan Kota di matacalon customer yang melihatnya.

\section{DAFTAR PUSTAKA}

[1] Aniendya Christianna 2018, Moeljadi Pranata. Karakteristik Desain Poster Film Animasi Amerika Serikat. Jurnal Desain Komunikasi Visual Fakultas Seni dan Desain Universitas Kristen Petra no.28

[2] Soewito. Yudhi. 2016. Kualitas produk, merek, dan desain pengaruhnya terhadap keputusan pembelian sepeda Motor Yamaha Mio, JurnalEMBA, Vol 1, No. 3, Juni : 2303-1174

[3] Wibowo, Ibnu Teguh, 2013, Belajar Desain Grafis, Yogyakarta: BUKU PINTAR.

[4] Yuliati, Tri, Utami, Ema. Fatta, Al, Hanif. 2014. Perancangan Mobile Augmented Reality Dengan Metode Interactive Multimedia System Design Development (Studi Kasus: Brosur Di Sekolah Tinggi Teknologi Dumai). Yogyakarta. SMTIK AMIKOM. Jurnal DASI ISSN: 1411-3201 Vol. 15. No. 1

[5] Damayanti, Putri, Ivoni. Prabawa, Bijaksana, S.Ds., M.M. 2017. Perancangan Media Promosi Objek Wisata Taman Air Gua Sunyaragi Di Cirebon. Universitas Telkom. Jurnal e-Proceeding of Art \& Design. ISSN: 2355-9349. Vol. 4 No. 3 
[6] Maulani, Giandari. Janah, Nur, Siti. Yuri, Mahbubi, Alam. 2017. Desain Media Komunikasi Visual Berbentuk Tabloid Sebagai Sarana Promosi SMK Mandiri 2. Tangerang. STMIK Raharja. Jurnal Ilmiah SISFOTENIKA ISSN: 2087-7897 Vol. 7 No. 1

[7] Immaniar, Dewi. Sudaryono. Ningrum, Ayu, Dwi. 2014. Enriching Media Merchandise Sarana Penunjang Promosi Studi Kasus Pada Book-Store. Tangerang. STMIK Raharja. Jurnal CCIT. ISSN: 1978-8282 Vol. 7 No. 3

[8] Jiang, Yan. Wenlong Liu. 2015. Application of Mind Mapping in Poster Design Classroom Teaching and Practice Guiding. International Journal of Sociology Study. China: Dalian University of Technology.Vol 3 No.1:49 